\title{
Editorial
}

\section{Radiation hazards for the patient in cardiological procedures}

The radiation dose to both staff and patients in interventional cardiology and radiology procedures is high compared to diagnostic procedures, particularly in the cardiological techniques of percutaneous coronary intervention (PCI) and radiofrequency ablation as well as developing techniques such as direct myocardial revascularisation. In considering the potential harmful effects of radiation it is necessary to consider effects on the patients themselves as well as the staff performing the procedure. There is considerable experience relating to the exposure of staff and increasing awareness of the importance of radiation protection for the staff and patients. Regulations covering both groups have been in place for 10-15 years. The aim of this article is to review the radiation hazards to the patient and the radiation protection measures taken to ensure that the risk to the patient is kept as low as reasonably practicable. In addition it will review the newly implemented Ionising Radiation Regulations.

\section{Radiation biology}

There are two main biological effects of ionising radiation: deterministic and stochastic. Deterministic effects are those in which the number of cells lost in an organ or tissue is so great that there is a loss of tissue function. The harm will not occur below a threshold and above this the severity of the effect will increase with dose. Skin erythema and ulceration are examples of deterministic effects. Stochastic effects occur if an irradiated cell is modified rather than killed and then goes on to reproduce. The result may be the manifestation of a cancer after a prolonged and variable delay called the latent period. Stochastic effects do not appear to have a threshold and the probability of the effect occurring is related to the radiation dose. The International Commission for Radiation Protection (ICRP), an international professional body, produce recommendations which are the basis for the conceptual framework and key principles of radiation protection world wide. The current international recommendations ${ }^{1}$ (ICRP 60) lay out the principles of justification, optimisation, and limitation of all radiation exposures. While there are no specified dose limits for patients, the main principle is that all deterministic effects should be avoided while optimising radiation exposure to gain maximum diagnostic accuracy with minimum dose.

In most interventional procedures the doses are such that only stochastic effects need to be considered for radiation protection purposes, but recently a number of cases of skin erythema, necrosis and ulceration have been reported in the USA $^{23}$ and Europe. ${ }^{4}$ The case reports ${ }^{5}$ published recently in this journal are two such examples. Unfortunately such problems generally come to light when reported by others and so there is usually little information about the procedure and radiation doses used to produce the damage as in the current reports. Nevertheless such cases serve as important examples of how things can go wrong.

\section{Radiation dosimetry}

The measurement of radiation and indicators of its effects are represented in a number of ways. Absorbed dose, unit gray (Gy), is a measure of the energy deposited in tissue. The quantity equivalent dose (ED), unit sievert (Sv), has been developed to allow an estimate of the risk of stochastic effects in a particular tissue taking into account the effect of different radiations. For diagnostic $x$ rays these two quantities are numerically equal. The quantity effective dose unit, also the sievert, takes a weighted mean of the equivalent dose in each tissue allowing for the different tissue sensitivities, thus allowing the comparison of risks from exposure of completely different tissues. While absorbed dose in particular organs can be measured in tissue equivalent phantoms, absorbed dose in patients can only be extrapolated from other measurement values such as entrance skin dose and dose area product. Entrance skin doses (ESD) can be measured for individual patients using small tissue equivalent thermoluminescent detectors placed on the skin surface or indirectly using radiographic exposure factors and measured $x$ ray tube characteristics. However, the risk to the patient from stochastic effects will depend not just on the ESD but also the volume of tissue irradiated and the sensitive organs irradiated. The dose area product (DAP) meter has been developed to give the product of the absorbed dose and the field area. Effective dose can be calculated from ESD or DAP readings (usually using computer systems) using extensive tabulated factors ${ }^{6}$ if the $x$ ray beam characteristics and the projections used are known.

The radiation dose to an individual patient will vary considerably depending on the patient's characteristics, distance from $x$ ray source, tissues irradiated, and so forth. Even if these factors are known, there will be some uncertainty in the dose absorbed by the patient. The implementation of the current radiation protection regulations has taken place in the light of the complexities resulting from uncertainties concerning dose.

\section{Ionising radiation regulations}

Until 1 January 2000, UK radiation protection legislation was based upon a close interpretation of the 1977 ICRP $^{7}$ recommendations. The Ionising Radiations Regulations $1985^{8}$ provided regulation for workers and members of the public and, of course, applied to the use of ionising radiation in medicine. The Ionising Radiation (Protection of Persons Undergoing Medical Examination or Treatment) Regulations $1988^{\circ}$ (POPUMET) were designed to address the protection of the patient. The aim of POPUMET was to ensure that individuals took responsibility for every medical exposure and that they were properly trained so that they understood the risk of the radiological examination, and were able to balance it against the patient benefit. This led to the definition of the terms "clinically directing" and "physically directing"; the person "clinically directing" the exposure would usually be a medical practitioner, while the individual "physically directing" the exposure would normally be a radiographer or an $x$ ray technician. Those responsible for "clinically directing" an exposure, who were not already fully trained in radiation protection as demonstrated by professional qualification, were required to be trained in the "core of knowledge" defined in the legislation in addition to practical training. 
Table 1 Roles of the referrer, practitioner, and operator in three typical clinical scenarios

\begin{tabular}{|c|c|c|c|}
\hline $\begin{array}{l}\text { Clinical examples of different } \\
\text { scenarios }\end{array}$ & $\begin{array}{l}\text { Conventional radiology referral for } C T \\
\text { scan }\end{array}$ & $\begin{array}{l}\text { "Mixed" involvement in PCI (physician } \\
\text { refers a patient to a cardiologist; a } \\
\text { non-interventional cardiologist refers a } \\
\text { patient to an interventional radiologist) }\end{array}$ & $\begin{array}{l}\text { "Pure" cardiological involvement in PCI } \\
\text { (patient referred directly to an interventional } \\
\text { cardiologist who also performs the procedure) }\end{array}$ \\
\hline \multicolumn{4}{|l|}{ Duty holder } \\
\hline Referrer & $\begin{array}{l}\text { Normally a referring clinician. This } \\
\text { person need not have any knowledge } \\
\text { of radiation protection but must } \\
\text { impart sufficient clinical information } \\
\text { to the practitioner to permit proper } \\
\text { assessment of the risks and benefits of } \\
\text { the proposed examination. }\end{array}$ & $\begin{array}{l}\text { A cardiologist or physician who refers a } \\
\text { patient to a specialist in PCI, providing } \\
\text { sufficient clinical information for the } \\
\text { specialist to judge that PCI is indicated. }\end{array}$ & $\begin{array}{l}\text { The clinical cardiologist who clinically } \\
\text { assesses a patient themselves and decides } \\
\text { they require PCI. }\end{array}$ \\
\hline Practitioner & $\begin{array}{l}\text { Normally a radiologist. This } \\
\text { individual must understand fully the } \\
\text { radiation risks of the procedure and } \\
\text { the potential benefits and will justify } \\
\text { the examination. }\end{array}$ & $\begin{array}{l}\text { The specialist, usually a cardiologist, who } \\
\text { justifies the PCI and usually performs the } \\
\text { clinical and catheter related aspects of the } \\
\text { procedure, having evaluated the risks and } \\
\text { benefits of the procedure, including those } \\
\text { related to radiation exposure. }\end{array}$ & $\begin{array}{l}\text { The same cardiologist who lists his patient } \\
\text { for a PCI procedure, having evaluated the } \\
\text { risks and benefits of the procedure, } \\
\text { including those related to radiation } \\
\text { exposure (justifying the exposure). }\end{array}$ \\
\hline Operator & $\begin{array}{l}\text { This would typically be a radiographer } \\
\text { who was fully trained in operating the } \\
\text { equipment and as such would } \\
\text { understand the means of optimising } \\
\text { diagnostic quality while minimising } \\
\text { patient radiation dose. The individual } \\
\text { would authorise the exposure. }\end{array}$ & $\begin{array}{l}\text { This would often be the cardiological } \\
\text { specialist (authorising the exposure, } \\
\text { operating the angiographic equipment, } \\
\text { including the adjustment of the } \\
\text { equipment and the initiation of } \\
\text { exposures), but might be a radiographer } \\
\text { assisting the PCI specialist by operating } \\
\text { the equipment. }\end{array}$ & $\begin{array}{l}\text { The same cardiologist who operates the } \\
\text { angiographic unit during the procedure, } \\
\text { including the adjustment of the } \\
\text { equipment and has authorised the } \\
\text { exposure. }\end{array}$ \\
\hline
\end{tabular}

CT, computed tomographic; PCI percutaneous coronary intervention.

Following the production of the new international recommendations ${ }^{10}$ (ICRP 60), two new European directives concerning radiation protection have been produced. The Basic Safety Standards Directive ${ }^{11}$ deals with the radiation safety of staff and members of the general public and was implemented in the UK by the Ionising Radiations Regulations $1999^{12}$ (IRR99) which came into force on 1 January 2000. The Medical Exposure Directive ${ }^{13}$ deals with the protection of patients and was implemented by the UK in May 2000. This legislation is known as the Ionising Radiation (Medical Exposure) Regulations 2000 (IR(ME)R2000 $)^{14}$, and is more extensive than POPUMET to reflect the directive's increased scope and detail.

The concept of clinically and physically directing does not appear in IR(ME)R2000 but a number of "duty holders" are identified. The employer must provide a framework for radiation protection through the provision of standard operating procedures. Each individual medical exposure must be justified by a "practitioner" but the "referrer" must provide sufficient relevant clinical information to allow that justification to take place. The "operator" takes responsibility for the practical aspects of the medical exposure. Medical responsibility for the patient will remain with the clinician responsible for that patient (who may be the referrer or the practitioner), while clinical responsibility for the medical exposure will rest with the practitioner.

In conjunction with the three named "duty holders" there are three specific steps that must be undertaken in any medical exposure. The first step is "justification" which recognises the net benefits of the procedure taking into account the clinical circumstances and the nature of the examination. The second step is "authorisation" which is necessary to confirm that a procedure can be carried out on a specific named patient at a particular time. The third step is the "practical aspect" which is the actual conduct of the procedure by operating the equipment that delivers the dose of ionising radiation. These steps are all required but may be carried out by different "duty holders" in differing circumstances.

Who undertakes the roles of the practitioner and operator will need to be agreed locally although both the practitioner and operator will have to be "experts in the use of radiation" and the regulations will require a considerable amount of combined practical and theoretical training. For those that do not hold professional qualifications relating to the use of radiation, the training will be in excess of the recent half or full day "core of knowledge" courses. All cardiologists who act in the role of a practitioner or operator, regardless of their status, will need to demonstrate that they have undergone adequate and appropriate training for the function they undertake. Schedule 2 to the IR(ME)R2000 regulations is quite specific and detailed in relation to the elements of theoretical knowledge and practical training that will be required for practitioners and operators under the regulations. Discussions with professional bodies including all the Royal Colleges are continuing to identify exactly what that training will be entailed for various professional groups. The Royal College of Physicians has a working party which includes a cardiology representative and this will advise on training requirements for cardiology procedures. There will not be a "grandfather clause" for training under POPUMET, although previous theoretical training and practical experience demonstrated may be taken into consideration.

In theory another suitably qualified person (such as a radiologist and/or a radiographer acting as practitioner and/or operator) participating in the procedure with the cardiological specialist could undertake the justification and practical aspects of the exposure. The cardiologist would direct the procedure as a whole with the radiological elements of the procedure being the responsibility of these other trained clinical staff. This is likely to occur in a minority of situations only and it is important to clarify that if the cardiologist justifies and/or authorises the exposure (acting as a practitioner) or undertakes any of the practical aspects of the exposure such as using the footswitch, setting exposure factors or controlling the projections (acting as an operator) then he or she will require training in the use of ionising radiation. For example, if the cardiologist uses the footswitch, even if there is a radiographer present in the room, he or she will require adequate and appropriate training in the use of ionising radiation.

The roles of the referrer, practitioner, and operator in three typical scenarios are shown in table 1 .

Intracoronary radiation therapy (IRT) is a special and complex case and must be considered separately. It would normally require joint cooperation between cardiology, 
Table 2 Review of recent literature giving mean patient doses for cardiac angiography techniques

\begin{tabular}{|c|c|c|c|c|c|c|c|c|c|c|c|c|}
\hline \multirow[b]{2}{*}{ Reference } & \multicolumn{4}{|c|}{ Coronary angiography } & \multicolumn{4}{|c|}{$P T C A / P C I$} & \multicolumn{4}{|c|}{ Ablation } \\
\hline & No & $E D(m S v)$ & $\begin{array}{l}D A P \\
\left(G y \mathrm{~cm}^{2}\right)\end{array}$ & $\begin{array}{l}E S D \\
(m G y)\end{array}$ & No & $\begin{array}{l}E D \\
(m S v)\end{array}$ & $\begin{array}{l}D A P \\
\left(G y \mathrm{~cm}^{2}\right)\end{array}$ & $\begin{array}{l}E S D \\
(m G y)\end{array}$ & No & $\begin{array}{l}E D \\
(m S v)\end{array}$ & $\begin{array}{l}D A P \\
\left(G y \mathrm{~cm}^{2}\right)\end{array}$ & $\begin{array}{l}E S D \\
(m G y)\end{array}$ \\
\hline Betsou et al $1998^{17}$ & 29 & 5.6 & 30.4 & & 12 & 6.9 & 37.6 & & & & & \\
\hline $\begin{array}{l}\text { Broadhead et al } 1997^{18} \\
\text { Room A }\end{array}$ & 2174 & 9.4 & 57.8 & & 214 & 14.2 & 77.9 & & 81 & 17.3 & 95.1 & \\
\hline $\begin{array}{l}\text { Broadhead et al } 1997^{18} \\
\quad \text { Room B }\end{array}$ & 126 & 4.6 & 23.4 & & 11 & 10.2 & 51.6 & & & & & \\
\hline Leung and Martin $1996^{19}$ & 90 & 3.1 & 14 & & & & & & & & & \\
\hline Vano et al $1995^{20}$ & 288 & & 66.5 & & 45 & & 87.5 & & & & & \\
\hline $\begin{array}{l}\text { Coulden and Readman } \\
1993^{21}\end{array}$ & & $3.0-5.7$ & $20-40$ & & & & & & & & & \\
\hline Pattee et al $1993^{22}$ & & & & & 91 & & & 1090 & & & & \\
\hline Zorzetto et al $1993^{23}$ & 39 & & 55.9 & & 31 & & 91.8 & & & & & \\
\hline Hwang et al $1998^{24}$ & 135 & & & 180 & 35 & & & 1021 & & & & \\
\hline Rosenthal et al $1998^{25}$ & & & & & & & & & 859 & $\begin{array}{l}25(\mathrm{~F}) \\
17(\mathrm{M})\end{array}$ & & 1300 \\
\hline Park et al $1996^{26}$ & & & & & & & & & 500 & & & 930 \\
\hline
\end{tabular}

PTCA, percutaneous transluminal coronary angioplasty; PCI, percutaneous coronary intervention; ED, effective dose; DAP, dose area product; ESD, entrance skin dose; $M$ male; $F$ female.

radiation oncology, and medical physics departments. These arrangements are covered by the Medicines (Administration of Radioactive Substances) Act $1978^{15}$ (MARS) and its amendment in $1995 .{ }^{16}$ These regulations are supervised by the administration of radioactive substances advisory committee (ARSAC) and staff involved in the use of radioactive substances in patients must be licensed by this committee.

\section{Clinical effects of radiation exposure}

There have been numerous publications that have estimated the radiation dose to patients having typical cardiological procedures. ${ }^{17-26}$ A summary of the results is presented in table 2. The dosimetric data are presented as effective dose, dose area product or entrance skin dose depending on the data source. The table illustrates that there is no consensus on the most appropriate dosimetric quantity. The variability of recorded doses is striking. This is likely to be explained by the large number of variable factors in recordings made in different institutions as well as the intrinsic difficulties of radiation dosimetry which is essentially an indirect technique. It should also be noted that different measurements such as the effective dose, the dose area product, and the skin dose do not always change in similar ways. In particular modern systems often use added copper filtration to reduce skin dose, but the reduction is not always reflected in the effective dose because of the higher effective energy of the $x$ ray beam.

These figures can be put into perspective by comparing the lifetime risk of cancer which has been estimated as approximately $5 \times 10^{-2} \mathrm{~Sv}^{-1}$ or 1 in 20000 per millisievert for adults in the $40-60$ age group. ${ }^{1}$ This means that a percutaneous coronary intervention giving a patient dose of $14 \mathrm{mSv}$ may add a 1 in 1400 risk of a cancer in an individual patient's lifetime. With 25000 percutaneous transluminal coronary angioplasty procedures being undertaken annually in the UK, this means that perhaps up to 20 patients per year will have a cancer caused by percutaneous coronary intervention at some future date. This is in addition to any immediate short term deterministic effects.

\section{Radiation protection in practice}

All UK hospitals must have a structure to implement and monitor radiation protection measures. There must be a qualified medical physics expert, normally the radiation protection adviser, to advise the hospital management and to produce detailed work instructions-"local rules"-which ensure that doses to staff and members of the public are as low as reasonably practicable. The individual departmental manager or director should have a radiation protection supervisor whose responsibility it is to ensure that the local rules are adhered to. The radiological procedure is expected to be carried out with attention to the ALARA principle ("as low as reasonably achievable") and in accordance with accepted diagnostic practice. As such, the final decision on radiation dose rests with the clinician in charge of the procedure. Following the recommendations of ICRP $60,{ }^{1}$ the IR(ME)R 1999 do, however, require constraints or "diagnostic reference levels" which are produced either locally or possibly nationally. These are dose levels that should not normally be exceeded, but if they are they should be reviewed by the employer and action taken where appropriate.

All procedures will have to be based on written protocols. It will be necessary for these protocols to allow adequate flexibility for the proper conduct of procedures, but they will be based on fundamental principles that are accepted as the basis of good practice. The IR(ME)R 2000 have a subsidiary clause which allows until 1 January 2001 for these written protocols to be established.

The more stringent requirements for training will need the development and implementation of new training programmes. Such programmes do not exist at this early stage, but it is likely that they will be developed locally. The training given will need to conform to both the legal regulations and the professional guidance that will be given by the Royal Colleges. The regulations are very new and at present there has been insufficient time for the new courses to be implemented; this will need to take place in the next few months.

A major part of radiation protection is the keeping of adequate records. Monitoring badges for staff are well accepted but it is only just becoming commonplace for radiation doses to patients (usually dose-area product, DAP) to be routinely recorded. The new regulations do not require that every medical exposure is individually recorded, but in each individual medical exposure there must be proper documentation of the justification, authorisation, and practical aspects (the equivalent of radiology requests and reports). In addition to this, regular detailed clinical audit is required which will allow assessment of untoward incidents and will allow the comparison of one $x$ ray machine with another or one $x$ ray department or operator with another. Records of departmental doses (local "diagnostic reference levels") should be kept in sufficient detail to allow reconstruction of a patient dose in the case of an incident that requires investigation. An incident involving an excessive radiation dose will need to be reported to the appropriate health department if there has been a procedural failure or the Health and Safety Executive if equipment has failed or malfunctioned. Up to date records of all equipment must be kept. 
It is also a requirement for the employer to keep accessible and up to date records of all practitioners and operators together with details of the nature of their training and the date the training was completed.

The responsibilities for compliance with these new regulations will ultimately lie with the employer, commonly a hospital trust in the National Health Service. The statutory legal instruments, supported by advice and protocols from the professional bodies which set out best practice, must be ultimately implemented by the employer. The new regulations will be interpreted variably at local levels, but each employer will ultimately be required to comply with these regulations in terms of training, protocols, record keeping, audit, and supervision.

\section{Cardiological procedures}

Interventional cardiology procedures are often difficult and stressful for the clinician who must keep many technical and clinical aspects in mind simultaneously. Coupled to this is the notion that the patient's cardiological condition carries a substantial threat compared to the radiation dose that is often ignored or considered negligible. There is also a factor of technical challenge associated with such procedures, namely that "success is everything" and the concept of discontinuing a procedure is seen a failure, even if in the patient's overall best interests. It is not surprising therefore that on occasions some overenthusiastic operators continue procedures for very long periods with prolonged screening times. It may be difficult for a radiographer or other staff member to remind the clinician of the radiation hazards and, if there is no radiographer present, then the difficulties are compounded.

Much radiation protection is common sense. The $x$ ray beam obeys the inverse square law and, as such, will deliver extremely high skin doses if the patient is not kept in the isocentre but is allowed to lie close to the $x$ ray tube. Proper collimation of the beam is essential. Steep cranial or caudal angulations are sometimes clinically indicated but they deliver much higher doses; they should only be used where necessary. The use of a single projection for a prolonged procedure will concentrate the radiation on one skin entry point, therefore projections should be varied whenever possible. Asking the patient to take a breath in will not only improve the image but will also decrease the radiation dose; of course, there will be difficult situations where an inspiration is not possible but there are many occasions where it is. If a patient has previous films and these are not reviewed then repeat studies could cause unnecessary radiation dose. Perhaps the most obvious but a nevertheless common mistake is related to the use of the screening pedal. If this is controlled by the cardiologist performing the procedure there is a risk of exposure being continued unnecessarily when the operator is not looking at the screen or is performing some non-essential manoeuvre such as watching an unchanging inflated balloon. Sometimes screening is also unnecessarily continued when projections are being changed.

The equipment used is a major variable. Modern digital systems with radiation limiting technology such as improved beam filtration or pulsed fluoroscopy can substantially reduce radiation dose. Upgrading an old unit can in itself be a major radiation reducing action.

Finally, although it has not been mentioned in this article, we should consider the whole issue of informed consent. It may soon be time to mention the risks from radiation exposure along with all the other risks of the intervention.

\section{Conclusions}

Radiation protection is often seen as a dry and dull topic, but it is becoming increasingly important particularly in interventional cardiology. All hospitals and cardiology departments have a legal duty to comply fully with the new regulations but it goes much further than this. Clinical governance requires that high standards of clinical practice are maintained by the responsible medical staff together with the hospital administration. The new regulations may require staff to change long standing practices and perhaps redirect resources to better control, monitoring, and audit of radiation exposures as well as more rigorous training in the use of ionising radiation.

Britain has traditionally maintained high standards of radiation protection practice. In times of changing clinical practice and professional regulation we must ensure that this high standard is maintained.

P WILDE E M PITCHER ${ }^{\star}$

Department of Clinical Radiology,

Department of Medical Physics $\mathcal{E}$ Bioengineering*,

United Bristol Healthcare Trust,

Bristol, UK

Peter.Wilde@ubht.swest.nhs.uk

K SLACK

Imaging Team,

Department of Health

1 International Commission on Radiological Protection. 1990. Recommendations of the International Commission on Radiological Protection. ICRP tions of the International Commission

2 Vano E, Arranz L, Sastre JM et al. Dosimetric and radiation protection considerations based on some cases of patient skin injuries in interventional cardiology. Br F Radiol 1998;71:510-16.

3 US Food and Drug Administration. Avoidance of serious X-ray induced skin injuries to patients during fluoroscopically guided procedures. Med Bull 1994;24:7-17.

4 Shope TB. Radiation-induced skin injuries from fluoroscopy. Radiographics 1996;16:1195-9.

5 Dehen L, Vilmer C, Humiliere C, et al. Chronic radiodermatitis following cardiac catheterisation: a report of two cases and a brief review of the literature. Heart 1999;81:308-12.

6 Hart D, Jones DG, Wall BF. Estimation of effective dose in diagnostic radiology from entrance surface dose and dose-area product measurements. NRPB-R262. Nrom entrance surface dose and dose-area product measurements.

7 International Commission on Radiological Protection 1977. Recommendations of the International Commission on Radiological Protection. ICRP tions of the International Commission
Publication 26. Ann ICRP 1977;1:3.

8 Anon. The Ionising Radiations Regulations 1985, (SI 1985 No 1333). London: HMSO.

9 Anon. The Ionising Radiations (Protection of Persons Undergoing Medical Examination or Treatment) Regulations 1988. London: HMSO.

10 International Commission on Radiological Protection. 1990 Recommendations of the International Commission on Radiological Protection. ICRP Publication 60. Ann ICRP 1991;21:1-3.

11 European Community. Council Directive 96/29/Euratom of 13 May 1996 laying down basic safety standards for the protection of the health of workers and the general public against the danger arising from ionising radiation. Official f Eur Commun 1996;39, L159.

12 Anon. The Ionising Radiations Regulations 1999, (SI 1999 No 3232). London: HMSO.

13 European Community. Council Directive 97/43/Euratom of 30 June 1997 on health protection of individuals against the dangers of ionising radiation in relation to medical exposures. Official $\mathcal{F}$ Eur Commun 1997; L180/22.

14 Anon. The Ionising Radiation (Medical Exposure) Regulations 2000, (SI 2000 No 1059). London: HMSO.

15 Anon. The Medicines (Administration of Radioactive Substances) Regulations 1978, (SI 1978 No 1006). London: HMSO.

16 Anon. The Medicines (Administration of Radioactive Substances) Amendment Regulations 1995, (SI 1995 No 2147). London: HMSO.

17 Betsou S, Efstathopoulos EP, Katritsis D, et al. Patient radiation doses during cardiac catheterisation procedures. Br f Radiol 1998;71:634-9.

18 Broadhead DA, Chapple CL, Faulkner K, et al. The impact of cardiology on the collective effective dose in the north of England. $\mathrm{Br} f$ Radiol 1997;70:492-7.

19 Leung KC, Martin CJ. Effective doses for coronary angiography. Br F Radiol 1996;69:426-31.

20 Vano E, Gonzalez L, Fernandez J M, et al. 1995. Patient dose values in interventional radiology $\mathrm{Br} \mathcal{F}$ Radiol 1995;68:1215-20.

21 Coulden RA, Readman LP. Coronary angiography: an analysis of radiographic practice in the UK. Brf Radiol 19 93;66:327-31.

22 Pattee LP, Johns PC, Chambers RJ. Radiation risk to patients from percutaneous transluminal coronary angioplasty. $\mathcal{F}$ Am Coll Cardiol 1993;22:1044-51.

23 Zorzetto M, Bernardi G, Morocutti G, et al. Radiation exposure to patients and operators during diagnostic catheterization and coronary angioplasty. Cathet Cardiovasc Diag 1997;40:348-51.

24 Hwang E, Gaxiola E, Vliestra RE, et al. Real-time measurement of skin radiation during cardiac catheterization. Cathet Cardiovasc Diag 1998;43:367-70.

25 Rosenthal IS, Mahesh M, Beck TJ, et al. Predictors of fluroscopy time and estimated radiation $\mathrm{M}$, Beck Tu, et al. Predictors of fluscopy time and cedures. Am 7 Cardiol 1998;82:451-8.

26 Park TH, Eichling JO, Schechtman KB, et al. Risk of radiation induced skin injuries from arrhythmia ablation procedures. Pacing Clin Electrophysiol 1996;19:1363-9. 